The quiet organization - why a common language does not always create a linguistic community - By: HANNE TANGE

Posted by Michael Lambarena on December 222009 01:48:30

\title{
The quiet organization -why a common language does not always create a linguistic community
}

Imagine an office environment in an international company in Denmark. Around you employees are going about their daily routines. They write e-mails while chatting to their neighbours, exchange a few comments on their way to the photocopier, and gather in the break to discuss their boss, holiday plans or news on a joint project. Try then to imagine the same space, only without the noise: A work environment where employees perform their duties quietly and most of the chit-chat has disappeared. This is the situation in many organizations that have adopted English as their corporate language. In spite of arguments for a common medium, Danish employees find that the language change has implications for social interaction within the workplace; that the corporate language does not facilitate the informal and relaxed style of communication that they associate with conversations in their mother tongue.

The quiet organization has also become apparent at the Danish universities. In the canteens, the caterers shut up because they lack English names for main ingredients in frikadeller or tarteletter. In the Study Administration the secretary passes on a phone call because she prefers not to deal with queries from the foreign students or staff. Inside the lecturing theatres, teachers note how classroom discussions never seem to work in the international courses, and they long for the lively, jocular atmosphere that they have recalled from their Danish-medium classes. The students, on the other hand, are busy acquiring a scientific vocabulary in their second language and find it difficult to formulate questions or comments in English. As a result, they withdraw from classroom debates, leaving the lecturer to do all the talking.

The behaviours described above have been observed in Danish organizations that have adopted English as their working language. In the following I shall provide a more detailed account of the quiet organization, highlighting some of the social and linguistic processes 
that motivate such practices. My key arguments are that internationalisation involves more than a linguistic change, and that the introduction of English as a common language does not always lead to the establishment of a linguistic community.

\section{How did English become so important?}

There are a number of tendencies that have contributed to the growth of English within Danish private and public organizations. Foremost among these are globalization, the knowledge economy and Danish attitudes towards the English language.

Globalization may be understood as an external and internal change. On the one hand, globalization represents an outwards movement towards foreign markets, partners and destinations. This development has strengthened the global position of English, which is recognized world-wide as the business lingua franca - the medium adopted when we lack sufficient knowledge of French, Spanish, Persian or Mandarin. On the other hand, globalization can be interpreted as an internal process. As we go about our everyday routines, we meet a growing number of people who are not Danish, and regardless of whether they arrive as refugees, doctors or students, they are representatives of global change. In the workplace, their numbers continue to grow, and as many have no Danish language skills, they will use English when addressing their colleagues.

At the same time we have witnessed a transition from traditional manufacturing to a so-called "knowledge economy." The knowledge economy builds on technological innovation and a highly educated workforce, and in Denmark this combination has lead to growth in areas such as environmental technology, pharmaceuticals and telecommunications. The knowledge economy strengthens the position of English for two reasons: First, knowledge workers are recruited internationally, which adds to the number of non-Danish speakers within the workplace. Second, knowledge work is expensive, and in order to make the most of investments in language-intensive tasks such as software development and communications, companies frequently choose English which offers the broadest possible access to foreign customers and markets.

But perhaps the principal reason for English domination is language attitudes in Denmark. As Bent Preisler (1999) has demonstrated, many Danes assume that their proficiency is adequate for a range of everyday functions and will often welcome an opportunity to practice their English. Indeed many Danes are so happy Englishusers that they automatically switch into the second language when spotting a British or American accent, thus making it hard for native 
English speakers to learn Danish. The Danes' welcoming attitude has made it easy for managers to introduce English as a working language in companies and universities. Many employees think that they are absolutely fine working in the second language, and the rest will probably remain silent. For in an international work environment, there is limited room for people who cannot manage in English.

\section{Two qualitative studies}

The concept of the "quiet organization" emerged as part of a joint project with Jakob Lauring. During fieldwork in a large multicultural company he noted a strange silence in the offices - the absence of the noise that tends to accompany employees' execution of various tasks. Taking as a departure a collection of interviews with employees in fourteen English-speaking corporations we investigated the linguistic and communicative processes that motivate this silence. This brought us to the conclusion that the use of English as a corporate medium in Danish companies may hinder rather than facilitate cross-cultural cooperation and networking.

This preliminary conclusion has later been confirmed by a second project. Since 2007 I have interviewed university lecturers in an attempt to collect their experiences with the ongoing internationalization of higher education. A recurring theme in these conversations is language, with respondents identifying a series of problems arising from the request that they communicate highly specialized knowledge through their second language. Many lecturers associate English-medium classes with less interaction, lower academic standards, and, on the whole, a less interesting teaching experience.

In order to make sense of such findings, I should like to examine them in relation to the linguistic and communicative behaviours that seem to arise in response to the demand that Danish staff use English. I will therefore proceed with an examination of the twin practices of language clusters and thin communication.

\section{Language clusters}

The concept of language clusters describes our tendency to seek out people who speak our own language. You have probably witnessed it at international conferences where Danish, German, American and Spanish groups soon emerge. Or at the football or scout camps where we discover that some people are easier to talk to than others. Perhaps because we share a language, for given the choice, most of us prefer exchanges in our mother tongue. Alternatively, 
we may see the formation of Nordic alliances composed of Danes, Swedes and Finns, who will use English as a shared medium. Within this speech community language users are likely to agree that English spoken with a Scandinavian accent is fairly easy to understand, while alternative variants such as Spanglish or Chinglish are less accessible.

In multicultural companies language clusters arise in a range of situations. When attempting to solve specific tasks, Danish employees admit that they prefer to consult a compatriot rather than seek out the expert who happens to be foreign. This practice clearly undermines corporate language policies as the argument for introducing English is that it facilitates cross-cultural exchanges and networking. Yet employees observe that they find it both easier and faster to interact in their native language.

A second practice uncovered by our research is the tendency by the natives to use Danish when meeting over lunch or coffee. Not surprisingly we often hear this from foreign staff as it has implications for their ability to socialise with their Danish colleagues. However, it is important to recognise that this behaviour is not a symptom of Danish reservation or prejudice. Such practices emerge among the Danes because they represent the linguistic majority within their organization, and similar behaviours can probably be observed among Spanish staff in Madrid or Austrian staff in Vienna. To employees who are not Danish-speaking, the use of Danish during breaks represents a barrier to their participation in the organization's social life. In many work environments employees arrange nights out, a Friday beer or the Christmas party over a cup of coffee, and if you play no part in these initial negotiations, you are less likely to partake in the events.

Moving into the international classroom, clusters are particularly apparent before and after lectures. In classes with big groups of students from similar linguistic backgrounds, lecturers will hear in the breaks Chinese coming from one corner of the room, French from another, and at the back of the lecturing theatre the single Mexican joins forces with the four Spaniards. Indeed, this tendency to form speech communities is so evident in international education that experienced lecturers attempt to break up the clusters through the formation of multilingual project groups.

Lecturers also comment on the Danish preference for their native speech. Most respondents accept that the local students talk in Danish during the breaks because, as they put it, we all need to "relax" in a language that we master. In comparison, many find it problematic when local students use Danish when asking about 
scientific and practical problems. For even if such exchanges mainly occur during the breaks, the foreign students will have similar questions, and they can only follow these conversations when they are performed in English. On the whole, the lecturers are conscious of the need to answer their students in English. However, if the Danes persist, most teachers will switch into Danish. As one respondent puts it, you do not know whether the local students choose Danish, because they are simply not capable of engaging in a scientific discussion in English.

Regardless of whether you ascribe them to linguistic weaknesses or a need to relax in your mother tongue, language clusters represent a serious challenge to cooperation across linguistic boundaries. In response to their encounter with Danish-speaking cliques, foreigners may seek to establish their own alternative groupings, which can lead to the creation of parallel communities within the international organizations. At the same time, clustering often results in a marginalisation of international staff and students. Many foreigners express a wish to interact with their Danish colleagues, but also that they find this hard to achieve. Their main suggestion to people in a similar situation is to learn Danish, which seems paradoxical given the promise by international companies and universities that you can work in English.

\section{'Thin' communication}

Communication becomes thinner when people either choose to withdraw from exchanges in English or limit these to formal situations such as meetings or presentations. This kind of behaviour is closely related to the introduction of an English lingua franca, and yet it has proved hard to document. You cannot really ask in a questionnaire about language usage in conversations that never happened in the first place. Nevertheless, thin communication is a phenomenon many recognise. They may have witnessed it at the departmental meeting where employees are talking away until the chairperson announces the first point on the agenda, and people are expected to use English. Some have even contributed to the dilution by choosing not to tell their jokes or anecdotes in English because they fear their puns will not translate into the second language.

Employees characterise thin communication as a change in the atmosphere within their workplace. Often they cannot say what exactly has happened, but stress that the mood of their organization is no longer the same. One reason might be that the change into English has influenced the way employees talk to one another. That Danish humour disappears because it relies on linguistic subtleties that do not work in another language. A second 
reason is the formalisation of employee interaction. When people withdraw from all unnecessary conversations in English, staff meetings become the principal platform for employee exchanges, and they cannot facilitate the same kind of informal chit-chat as the coffee breaks.

A possible explanation for employees' withdrawal from interaction is linguistic uncertainty. Even when they have enough English to perform routine tasks in this language, many non-native speakers find that they lack the linguistic registers required in informal exchanges. In other words, they can present a project in a highly sophisticated, scientific terminology, but experience difficulties when attempting to tell a joke or a story. Employers do not request that people partake in organizational small-talk, however, and employees who fear that their English is inadequate, can avoid an exposure of such weaknesses by steering clear of any unessential exchange in the second language. In consequence, the quantity and quality of informal communication often decline in an Englishspeaking environment.

One group that is particularly vulnerable to linguistic dilution is the university teachers. Mostly the lecturers possess a fully developed vocabulary relating to their areas of expertise and only rarely experience difficulties when requested to present their scientific knowledge in English. However, in a teaching situation many will want to illustrate their theories through references to everyday situations or examples, and this is where they experience difficulties. Perhaps the lecturers leave out the personal stories they would normally use in the Danish classes to back up a specific claim, because they cannot make them work in the second language. Perhaps they come to regard international classes as less fun because they lack the English words and phrases that allow them to tell jokes.

In the lecturing theatres dilution also takes the form of missing interaction between students and the teachers. Although they have mostly accepted that their education is now in English, many local students opt for a more passive role. This may reflect the students' linguistic capacity for even when they can follow lectures in English they do not necessarily have the ability to formulate scientific arguments or questions in their second language. So if they know the lecturers will respond to a Danish question during the break, they may be tempted to postpone any queries that they have. But the students' quiet behaviour also seems to arise from the diversity within the international classes. That there are students present who may not be used to talking in class. They will only respond when approached directly by the teacher and their passive 
behaviour contributes to the silence.

This "thinning" of communication has serious implications for organizations' informal information systems. When they stop exchanging anecdotes and gossip, employees lose an important forum for networking and knowledge sharing. The Danes will probably resolve the situation through the establishment of speech communities that can accommodate their need for Danish humour and linguistic puns. Unfortunately, this leaves foreign staff with the impression that the locals do not really want to engage with them. Their only access to feedback is through departmental meetings and presentations, which rely on a more formal, task-oriented style of interaction. As a result, the cross-cultural dialogue, which was the motive for introducing English in the first place, never really takes off.

\section{Implications of the research}

There are two reasons why we need to be aware of the trends that have lead to the emergence of quiet organizations in Denmark. First of all, we need to address the issue from the perspective of the employees. For is it really fair when managers request that specialists in engineering or economics work in a language that they have not developed since they left high school? Or that we expose good lecturers to poor student evaluations because they lack the linguistic registers that will make biology or chemistry accessible to their students? Sometimes you wonder whether the policy-makers have introduced English without consulting their employees. That perhaps they believe you can change languages in the same way as you turn on the light - you press the button and then we all speak English.

At the same time we need to take into account the societal implications of this ongoing internationalisation. Do we need more English lessons in the primary and secondary schools so we can improve the Danes' capacity for working in the second language? Or do we need a language policy to tell us when employees have the right to use their mother tongue in the workplace? I guess I belong somewhere in between these two extremes, for I believe it is possible to accommodate both Danish and English within the international organizations. However, before we can reach this goal, we shall need a careful consideration of how much English internationalisation actually demands, identifying both the situations where it makes good sense to speak in English, and those where we might as well use Danish. We need an informed, research-based discussion, in other words, in order to work out the proper balance between Danish and English in Danish companies, higher education 
and civil society at large.

The original version of the article first appeared in the Danish journal Maal og Mæle in December 2008. The English version has been translated by the author and is reprinted with the permission of the editors.

\section{Author}

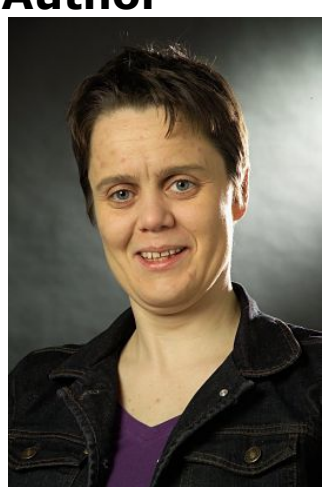

Associate professor Hanne Tange works in the Department of Language and Business Communicatiol Aarhus School of Business. She specialises in the field of cultural theory, intercultural communication and internationalisation.

This article was uploaded to http://www.languageatwork.eu in July of 2009 and published under a "Creative Commons license Attribution Non-commercial (by-nc)" for more information please go to: http://creativecommons.org/about/license/ 